\title{
Accurate Linking of Lake Erie Water Level with Shoreline Datum Using GPS Buoy and Satellite Altimetry
}

\author{
Kai-Chien Cheng ${ }^{1, *}$, Chung-Yen Kuo ${ }^{2}$, C. K. Shum ${ }^{3}$, Xutong Niu ${ }^{4}$, \\ Rongxing $\mathrm{Li}^{4}$, and Keith W. Bedford ${ }^{4}$ \\ ${ }^{1}$ Department of Earth and Environmental Sciences, National Chung Cheng University, Chiayi 621, Taiwan, ROC \\ ${ }^{2}$ Department of Geomatics, National Cheng Kung University, Tainan 701, Taiwan, ROC \\ ${ }^{3}$ Geodetic Science, School of Earth Sciences, The Ohio State University, Columbus, Ohio 43210, USA \\ ${ }^{4}$ Department of Civil and Environmental Engineering and Geodetic Science, The Ohio State University, Columbus, Ohio 43210, \\ USA
}

Received 15 November 2006, acceepted 23 June 2007

\begin{abstract}
There is a need to accurately link the water level to the shoreline vertical datum for various applications including coastal management, lake/river/estuary/wetland hydrological or storm surge modeling/forecasting. Coastal topography is historically surveyed and referenced to the predetermined vertical datum in terms of orthometric heights, or the heights above the geoid, which is poorly known in terms of accuracy and lack of adequate spatial resolution for coastal applications such as estuary or storm surge modeling. We demonstrate an accurate linking of the lake surface to a shoreline datum using satellite techniques, including GPS buoy and satellite altimetry, water level gauges, and local geoid and lake circulation models. The possible error sources are analyzed and an error budget is reported in this study. An innovated method to estimate geoid height near the water level gauge using a GPS buoy is proposed. It is found that at a 95\% confidence interval, the method is consistent with the National Geodetic Survey GEOID03 geoid model. The lake surface represented using a lake circulation model provided by the Great Lakes Forecasting Systems is also verified with kriging based on the data (1999 - 2001) from the water level gauge, and TOPEX/POSEIDON altimeter. Mean discrepancies of 2.7 and $7.2 \mathrm{~cm}$ are found with the data from the gauges around Lake Erie, and from the combination of the gauges and the altimeter, respectively. It reveals that the current dominant limitation of more accurate linking of water surface to shoreline is the insufficient knowledge of geoid in the current models. Further improvement is feasible through more accurate and higher resolution modeling of the lake geoid.
\end{abstract}

Key words: Satellite altimetry, GPS buoy, Water level gauges, Geoid

Citation: Cheng, K. C., C. Y. Kuo, C. K. Shum, X. Niu, R. Li, and K. W. Bedford, 2008: Accurate linking of Lake Erie water level with shoreline datum using GPS buoy and satellite altimetry. Terr. Atmos. Ocean. Sci., 19, 53-62, doi: 10.3319/TAO.2008.19.1-2.53(SA)

\section{INTRODUCTION}

There are various forms of geospatial data and models available in the coastal area, many of which have been independently collected with different purposes without the consideration of an integrated use for interdisciplinary applications. For example, coastal topography is represented by digital elevation models (DEM). Coastal circulation and hydrological or estuary models are referenced to a predetermined surface, which is close to an equipotential surface, assuming hydrostatic equilibrium. The water variation with

\footnotetext{
* Corresponding author

E-mail: cheng.168@ccu.edu.tw
}

respect to the equipotential surface is expressed in terms of the orthometric height, or the heights above the geoid. The tide or water level gauges measure lake level in terms of the height relative to the local benchmarks. Modern geodetic and remote sensing sensors such as the Global Positioning System (GPS), Light Detecting and Ranging (LIDAR), and satellite altimetry acquire measurements of topographic or water level heights, referenced within the International Terrestrial Reference Frame (ITRF), and often expressed as the ellipsoidal height above a reference ellipsoid. Many coastal applications, such as lake forecasting and hydrological modeling, environmental monitoring, coastal zone management, 
flood mitigation, relief dispatch during and after disasters, and governmental decision-making, require multiple geospatial data sources that are available in the coastal area. For example, Li et al. (2002) generated a digital tide-coordinated shoreline with multiple data sources including satellite techniques and the conventional methods primarily to support the coastal zonal management. Such information is very important in the flood zone identification, storm surge modeling/forecasting and other environmental monitoring. The linking of the lake surface, which is manifested by various modeling or observations, to a shoreline datum is thus critical.

Satellite altimetry has proven to be an efficient tool to observe precise water surface height $(<3 \mathrm{~cm}$ RMS error) with a spatial resolution of $\sim 50 \mathrm{~km}$ and a temporal resolution of 1 - 2 weeks (Chelton et al. 2001). The altimeter water surface height is measured along its ground tracks, which cross the water bodies being observed. On the other hand, the coastal water level gauge is a conventional means to measure the water level but its location is often limited to near the coastal region. Therefore, geographically speaking, the altimeter data and the water level gauge records are complementary to each other. However, they also complement each other in the temporal sense: many gauges in the Great Lakes have a long-term record up to several decades, whereas the effective use of satellite altimetry in observing water surface height has only been 15 years or so. The combined use of both data sets is thus advantageous.

The primary goal of this study is to demonstrate the link of the lake surface to a shoreline datum using multiple data sources, including water level gauges, satellite altimetry, GPS buoy, and the available models such as the circulation model of the Great Lakes Forecasting System (GFLS) (Bedford et al. 1990) in Lake Erie. It is intended to analyze the possible error sources and the current limitation in this area. Similar studies can be found in, e.g., Parker et al. (2003) who conducted a program in the National Geodetic Survey (NGS) of the US to incorporated data in the coastal area, including DEM, leveling, and GPS measurements. Although such capability is anticipated for all coasts in the US, the current version (1.06, as of November 2006) is only available to 6 coastal regions, in which Lake Erie is not included.

In this study, we use a novel technique involving the use of GPS water level and satellite altimetry observations to demonstrate the accurate linking of Lake Erie water level with the shoreline datum at the Marblehead and Cleveland water level gauges and the rest of Lake Erie. In the following sections, various vertical datums from the Great Lakes, methodology, and the error budget will be discussed. The accuracy assessment of an NGS geoid model (GEOID03) and a circulation model in Lake Erie provided by the GFLS is carried out with data from GPS buoy and satellite altimeter TOPEX/POSIEDON (T/P) lake surface measurements.
The developed methodology is generic and is applicable to other coastal regions worldwide.

\section{VERTICAL DATUMS AND THEIR CONVERSION IN THE GREAT LAKES}

There are various vertical datums available in the Great Lakes: Fig. 1 illustrates the ellipsoidal $(h)$ and the orthometric $(H)$ heights of the lake level at Point P. Based on the choices of the reference point, the lake level height at $P$ can be expressed in two ways: in terms of the ellipsoidal height above a geocentric reference ellipsoid; or in terms of the dynamic or the orthometric height above the geoid. The former is generally preferred by the satellite techniques, whereas the latter is conventionally used by leveling, DEM, and the water level gauges. The departure between the ellipsoidal surface and the geoid is the geoid height $(N)$ as shown in the figure and Eq. (1). Since the geoid is considered as an equipotential surface, the geoid height depends on the gravity potential and is thus location-dependent. Note that the orthometric height is measured along the curved plumb line but Eq. (1) is dealt with algebraically due to the negligible deflections of vertical in this area.

Heiskanen and Moritz (1987) mentioned that the gravity potential difference is a natural measure of height. As illustrated in Fig. 1, the geopotential number $(C)$ is defined in Eq. (2) as the potential $(W)$ difference between a given point $P\left(W_{P}\right)$ and the geoid $\left(W_{0}\right)$. Various heights are defined based on the geopotential number but we only discuss the dynamic and the orthometric heights here as they are rel-

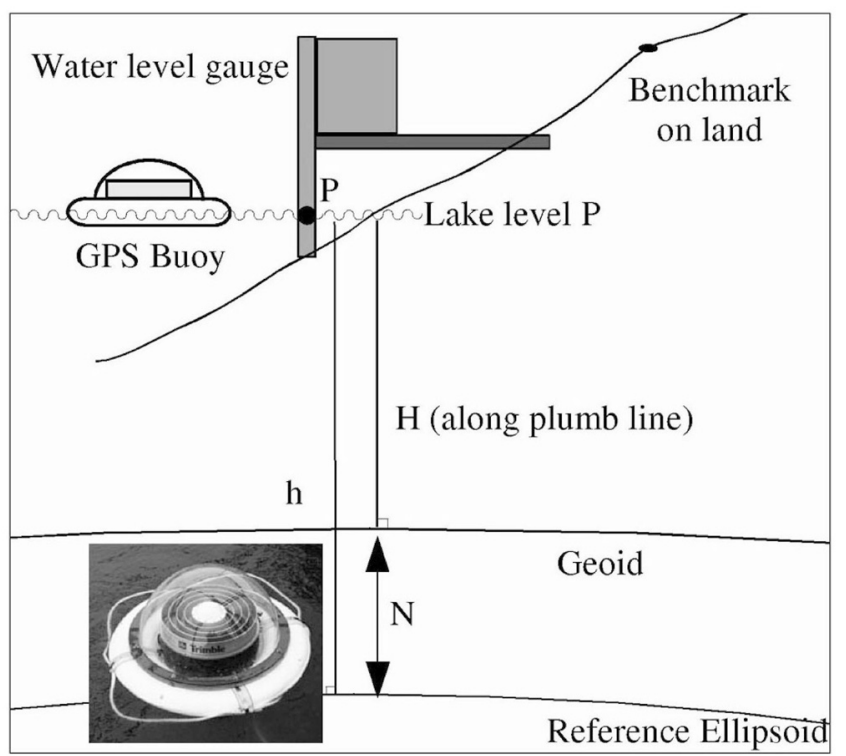

Fig. 1. Schematic diagram of the GPS buoy collocated at a water level gauge: $H, h$, and $N$ represent the orthometric, the ellipsoidal and the geoid heights, respectively. $W_{p}$ and $W_{0}$ refer to the gravity potential at lake level $\mathrm{P}$ and at geoid, respectively. The inset shows the wave-rider GPS buoy. 
evant to the data used in this study.

$N=h-H$

$C=W_{0}-W_{P}$

Heiskanen and Moritz (1987) defined the dynamic height $\left(H_{d y n}\right)$ and the orthometric height $(H)$ as the geopotential number scaled by a nominal normal gravity at $45^{\circ}$ latitude $\left(\gamma_{0}\right)$, in Eq. (3), and by an average gravity along the plumb line $(\bar{g})$, in Eq. (4), respectively. The dynamic height does not have the geometric meaning but rather is the potential difference relative to the geoid expressed in distance units (Jekeli 2000). The nominal normal gravity (980.6199203 gal) of the Geodetic Reference System of 1980 (GRS80) (Moritz 1992) is used in this study. On the other hand, the North American Vertical Datum of 1988 (NAVD88) is a common vertical datum of the orthometric height in the region (Zilkoski et al. 1992). The average gravity along the plumb line, $\bar{g}$, is approximated by using the surface gravity $(g)$ and its reduction according to Prey (Heiskanen and Moritz 1987). Therefore the orthometric height in Eq. (4) is calculated iteratively with geopotential number in $\mathrm{km} \cdot \mathrm{gal}$, the surface gravity in gal, and heights in $\mathrm{km}$.

$H_{d y n}=\frac{C}{\gamma_{0}}=\frac{W_{0}-W_{P}}{\gamma_{0}}$

$H=\frac{C}{\bar{g}} \approx \frac{C}{g+0.0424 H}$

The International Great Lakes Datum of 1985 (IGLD85) is the common datum in the Great Lakes for all the water level gauges maintained by the Center for Operational Oceanographic Products and Services (CO-OPS) of the US and the Marine Environmental Data Service (MEDS) of Canada. Due to various observational, dynamical, and steric effects, there is a small location-dependent departure from the gauge record in IGLD85 to the actual dynamic height, as defined in Eq. (3). This departure is known as the hydraulic corrector and ranges from -2.6 to $2.7 \mathrm{~cm}$ (Coordinating Committee on Great Lakes Basic Hydraulic and Hydrologic Data 1995).

It can be seen that the conversion between the gauge record in IGLD85 and the orthometric height can be achieved by equating Eqs. (3) and (4):

$H \approx \frac{H_{d y n} \cdot \gamma_{0}}{g+0.0424 H}=\frac{\left(H_{I G L D}+H_{C}\right) \cdot \gamma_{0}}{g+0.0424 H}$ in which $H_{I G L D}$ and $H_{C}$ are the gauge original record and the hydraulic corrector, respectively. Similarly, the orthometric height in the left had side of Eq. (5) needs to be calculated iteratively with the dynamic height as the initial approximation.

\section{LINKING OF WATER LEVEL TO THE SHORE- LINE DATUM}

The water surface height is conventionally realized by the observations of the coastal water level gauges. The gauges are limited onshore and thus the surface realized only by the gauges cannot sufficiently depict the entire lake. The measurements from satellite altimetry can be used to complement data collection in this situation since it provides precise water surface height along its ground tracks crossing the lake. The water surface height collected by satellite altimetry is in terms of the ellipsoidal height above a geocentric reference ellipsoid.

As we analyze Eq. (1), it is quite straightforward that the geoid height is required when it is desired to combine the data from the satellite techniques to the conventional methods. With an accurate geoid model, the entire lake can be precisely linked to the shoreline datum. The accuracy and the spatial resolution of the current geoid models are the main limiting factor in making the link. Hence, for the applications that demand higher precision, such as the calibration of satellite altimetry with coastal water level gauges (e.g., Shum et al. 2003; Cheng 2005), or precisely linking a bottom pressure gauge whose reference datum is arbitrary for sea level monitoring (e.g., Calmant et al. 2004), a survey at the gauge location with a GPS buoy is necessary in order to meet the stringent requirement in geoid height determination.

In this study, a floater-type GPS buoy (see the inset of Fig. 1) was deployed near two water level gauges located in the southern bank of Lake Erie (Fig. 2): Cleveland (Sept. 17 - 19, 2003) and at Marblehead (Oct. 20 - 21, 2001). It collected GPS codes and phases simultaneously with the gauge measurements as illustrated in Fig. 1. With the orthometric and the ellipsoidal heights obtained from the gauge and the buoy, respectively, the geoid height can be estimated with Eq. (1). Once the geoid height at the gauge locations is determined, the lake surface derived from the combined data of satellite altimetry, GPS buoy, and water level gauge are connected to a common reference system. As a result, the historical records of the gauge and of the satellite altimetry can be used for temporal analysis of the mean lake level, provided that the link is robustly established.

Since both gauges are located in the southern bank of Lake Erie, the link would have larger error in the northern part of the lake, assuming that the mean lake surface or the geoid model is imperfect. While the result of linking would be more accurate if more linking sites are available around 


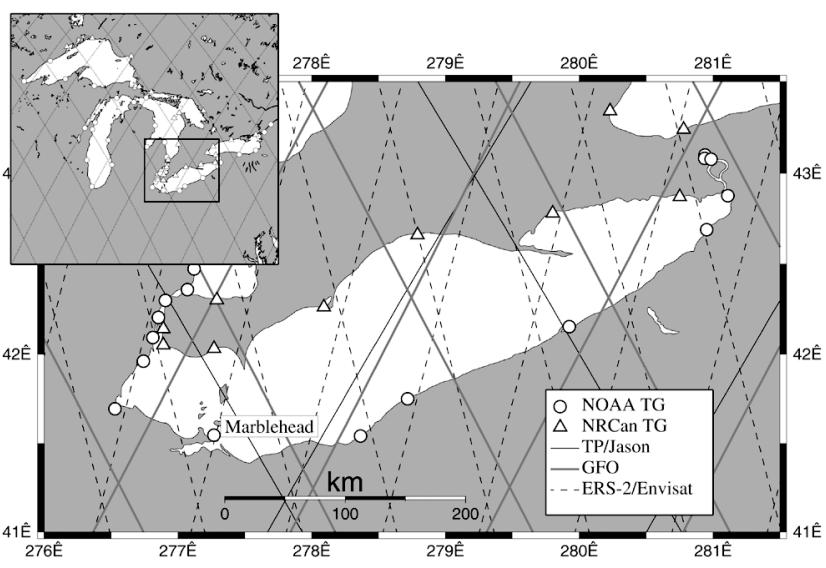

Fig. 2. The Lake Erie GPS buoy campaigns in Cleveland and Marblehead. The water level gauges (circles: American gauges; triangles: Canadian gauges) and the theoretical ground tracks of various satellite altimeters are shown. The ground tracks for the T/P altimeter and the water level gauges are shown in the inset covering the Great Lakes.

the entire Lake, the method developed in this study is robust and depends on the fidelity of the local geoid or the mean lake surface model.

Alternatively, the link of the shoreline datum, which is represented by the water level gauge measurements, to the satellite techniques can also be achieved by a GPS occupation at the benchmarks on land near the gauge. This method simplifies the fieldwork since it is carried out on land, allowing longer observation sessions. However, the link in this case is only made at the benchmark level, not the actual water level at Point P in Fig. 1. Although the geoid variation from the benchmark to the gauge is not likely to change rapidly, variations of the water level due for example to circulations do change. Thus, the vertical offset between the gauge's zero point and the benchmarks could be an error source, especially when the offset is time-varying. The gauge may have noticeable local vertical motion, as described in Section 4.3 for Lake Erie. Hence, this alternative is preferred only for the gauge that maintains a good record of the vertical offset from its zero point to the benchmarks, and is not as robust as our method developed for this study.

\section{ERROR BUDGETS}

\subsection{Verification of Geoid Models}

The local geoid height near Marblehead and Cleveland water level gauges was estimated with the GPS buoy. The GPS buoy, as seen in the inset of Fig. 1, consists of a Dorne/ Margolin Element with Choke Ring antenna, a radome, and a 2 -feet (diameter) life-saver buoy. The buoy is tethered to a boat where a Trimble 4000 SSI, a geodetic grade, dualfrequency receiver, power supply and the operators reside. Marks are made on four sides of the buoy and their offsets to the antenna reference point (ARP) are carefully measured in the laboratory. The operator needs to observe the water surface with respect to these marks a number of times during the observing session in order to accurately refer ARP to the water surface. Cheng (2004) reported the specifications of the buoy and the survey procedures for both campaigns.

Kinematic and Rapid Static (KARS), a GPS post-processing software developed by Mader (1986), was used to post-process the GPS buoy L1 + L2 phases using the differential GPS (DGPS) technique. The baselines between the buoy and the onshore reference stations were $122.4 \mathrm{~m}$ and $16.39 \mathrm{~m}$ at Marblehead and Cleveland, respectively. Due to the short baselines, typical L1 + L2 with phases and codes were post-processed with the kinematic mode using KARS. The sampling rate for the buoy was $1 \mathrm{~Hz}$ and the observation session was 6 hours at Marblehead and 1 hour and 40 minutes at Cleveland (due to security reasons, a longer occupation session was not allowed).

Since both campaigns were not carried at the same time, the coordinates were projected to the time epoch at midnight UTC on January 1, 2002 (2002.0), which is chosen in order to be consistent with the published coordinates of NGS' Continuously Operating Reference Stations (CORS) in this area. The height change due to this projection is insignificant $(<1 \mathrm{~mm})$.

The mean heights of GPS solution and of the water level gauge records were calculated. Consequently, the geoid height at these two locations was estimated with the means by using Eq. (1). Note the geoid height is the height above the GRS80 Reference Ellipsoid, projected at 2002.0 reference epoch. The precision of the 6-minute gauge record is $<2 \mathrm{~mm}$, as released by CO-OPS of the National Oceanic and Atmospheric Administration (NOAA) of the US along with the data. Because of the large amount of GPS observations, the estimated geoid heights at both locations reach 1-mm precision (see Fig. 3).

Figure 4 presents the reference surface and the relationship among the NGS geoid models: GEOID99, G99SSS, and G99BM. The details of such models are discussed in Roman et al. (2004). The GPS buoy-determined geoid height corresponds to the height of the NAVD88 datum (orthometric height) above/below the GRS80 Reference Ellipsoid. G99BM would have been the ideal choice for the verification but it was unavailable in Lake Erie. Based on the relationship shown in Fig. 4, two alternatives were adopted: Coordinate-transformed GEOID99 and G99SSS with $52-\mathrm{cm}$ bias applied.

In the first alternative, instead of using GEOID99, we chose GEOID03 for the comparison, which is the revised version of GEOID99 with updated data. The coordinatetransformed GEOID03 model means that a 7-parameter similarity transformation is applied to the original GEOID03 coordinates along with its model value. After applying the transformation to the GEOID03, the result essentially refers to the same reference surface as G99BM does (Dan Roman, personal communication, 2005). Note the change of the 
ITRF 2000 (2002.0) KARS Solution of GPS Buoy at Marblehead TG

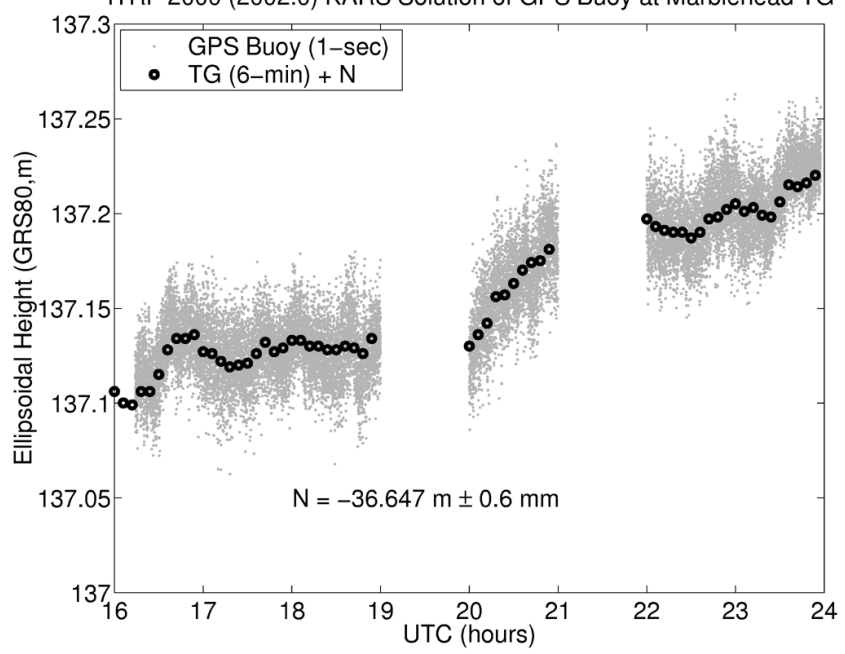

ITRF 2000 (2002.0) Solution of GPS Buoy at Cleveland TG

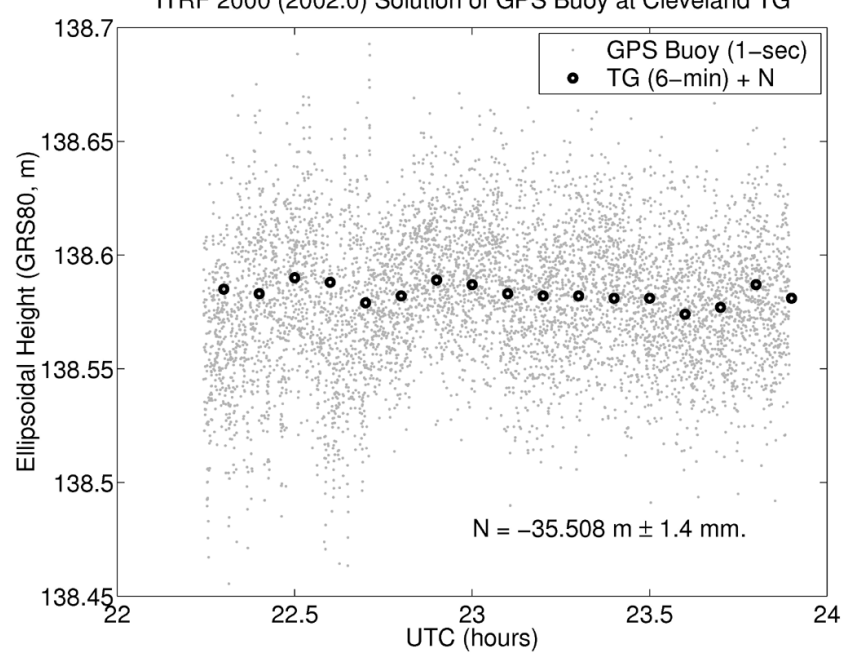

Fig. 3. The local geoid height $(N)$ in Lake Erie determined with a GPS buoy at Marblehead (left) and Cleveland (right). The lake levels observed at both gauges have been converted to the ellipsoidal height above the GRS80 Ellipsoid. TG denotes the lake level collected by the water level gauge every 6 minutes.

geoid model value due to this transformation can be seen in Fig. 5 in the amount of $\sim 1.2 \mathrm{~m}$ at both gauge locations. This is consistent with the 2-m offset between the origin of the North American Datum of 1983 (NAD83) and that of the ITRF found by Soler et al. (1992).

On the other hand, the use of G99SSS with $52-\mathrm{cm}$ bias applied was also checked. The results are presented in Table 1. The GPS buoy-determined geoid height agrees with the GEOID03 (after transformation) in the order of $-39 \mathrm{~mm}$ at Marblehead and $1 \mathrm{~mm}$ at Cleveland. The results are within $<2 \sigma$ of the current GEOID03 model, whose RMS error is $\pm 24 \mathrm{~mm}$ (Roman et al. 2004). This indicates that, at $95 \%$ confidence interval, the use of a GPS buoy to estimate geoid height is consistent with the GEOID03 model. The $52-\mathrm{cm}$ bias, which is a national average value provided by NGS in Fig. 3, is reasonably in agreement with the GEOID03 (after transformation) at the $10-\mathrm{cm}$ level.

\subsection{Conversion of Water Level Gauge Record to Ortho- metric Height}

Converting water level gauge records from IGLD85 to NAVD88 can be done by Eq. (5). Differentiating Eq. (5), the conversion errors from the gravity, the gauge records, and the hydraulic corrector can be analyzed as the following:

$$
\begin{aligned}
d H & =-\frac{\gamma_{0} \cdot\left(H_{I G L D}+H C\right)}{(g+0.0424 H)^{2}} d g+\frac{\gamma_{0}}{g+0.0424 H} d H_{I G L D} \\
& +\frac{\gamma_{0}}{g+0.0424 H} d H C
\end{aligned}
$$

where $d H$ in the left-hand side is the total conversion error in the orthometric height contributed by these factors. Without the real gravity observations involved in this study, the NGS gravity model interpolated from the NAVD88 general

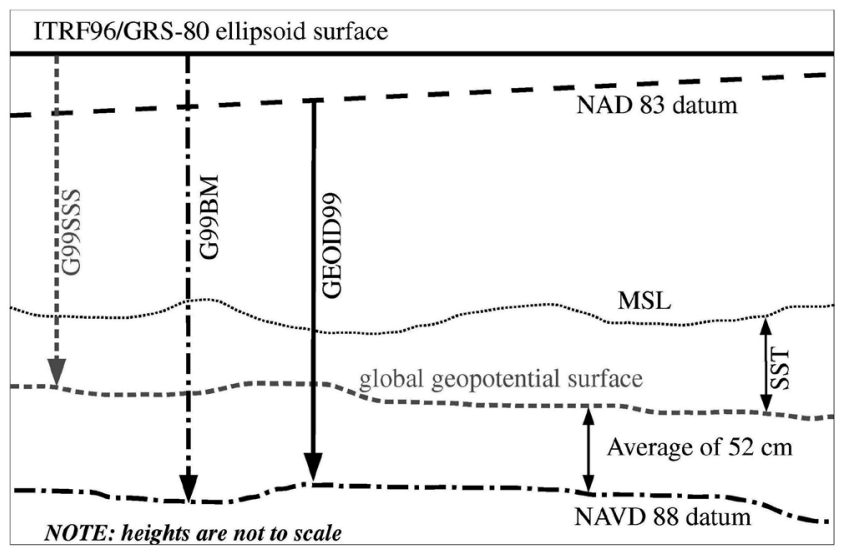

Fig. 4. The reference surfaces and the relationship among the NGS geoid models (National Geodetic Survey 2001). The 52-cm bias is provided by NGS that is the national average between the potential surface to the NAVD88 datum. MSL stands for mean sea level.

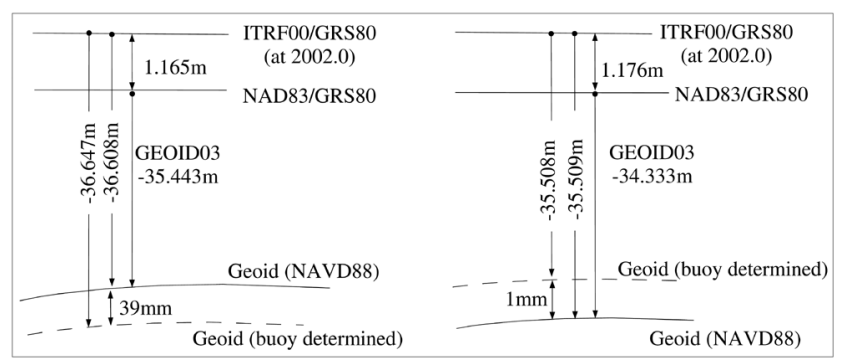

Fig. 5. Geoid height comparison at Marblehead (left) and at Cleveland (right). Three geoid height estimates in each case are, from left to right, GPS buoy-determined geoid height, the GEOID03 model value with the 7-parameter transformation applied, and the original GEOID03 model values. 
Table 1. The geoid height comparison at Marblehead and Cleveland gauges.

\begin{tabular}{lcc}
\hline & Marblehead & Cleveland \\
\hline GEOIE03 after coordinate transformation (representing NAVD88 wrt GRS80) & $-36.608 \mathrm{~m}$ & $-35.509 \mathrm{~m}$ \\
G99SSS with 52 cm discrepancy applied & $-36.637 \mathrm{~m}$ & $-35.606 \mathrm{~m}$ \\
GPS buoy-determined geoid & $-36.647 \mathrm{~m}$ & $-35.508 \mathrm{~m}$ \\
\hdashline$\quad \ldots \ldots \ldots \ldots \ldots \ldots \ldots \ldots \ldots \ldots \ldots$ \\
Discrepancy (G99SSS - GEOID03) & $-29 \mathrm{~mm}$ & $-97 \mathrm{~mm}$ \\
Discrepancy (GPS - GEOID03) & $-39 \mathrm{~mm}$ & $1 \mathrm{~mm}$ \\
\hline
\end{tabular}

adjustment was used in this study (National Geodetic Survey 2003). The average model gravity of the gauges in Lake Erie is $980.270 \mathrm{gal}$ and the average of the orthometric height and of the gauge records are 177.583 and $177.521 \mathrm{~m}$ respectively. Thus, the total conversion error, in $\mathrm{mm}$, becomes:

$d H \approx-200 \frac{\mathrm{mm}}{\mathrm{gal}} \cdot d g+1.0003 \cdot d H_{I G L D}+1.0003 \cdot d H C$

It can been seen that there is a 2 -mm conversion error contributed by every $10 \mathrm{mgal}$ of the gravity error and about a $1: 1$ ratio contributed by the IGLD85 gauge records and by the hydraulic correctors. The precision of airborne and satellite-based gravimetry is about $6 \mathrm{mgal}$ over $5 \mathrm{~km}$, and a few mgal over 50 - $100 \mathrm{~km}$ (Garcia-Lopez 1997). Therefore, gravity only contributes to the conversion error in mm-level if actual gravity data are used. The errors in the water level gauge records depend on the instruments, the benchmarks, and the dynamic and steric phenomena in the local lake surface that affect the hydraulic corrector.

The error sources of converting a water level gauge data from its original record in IGLD85 to geocentric height above the GRS80 Reference Ellipsoid is tabulated in Table 2. The error budget of the gravity and the hydraulic corrector are based on Eq. (7) with average height, normal gravity and average model gravity provided by NGS in Lake Erie. The hydraulic corrector is instrument-dependent and no error information is available at present. The dominant term is the geoid error. Roman et al. (2004) compared GEOID03 to GPS benchmarks in the US and found that the RMS error is $\pm 24 \mathrm{~mm}(1 \sigma)$ including the errors from modeling, GPS and leveling observations. Due to lack of gravity observations on the lake in the development of the geoid models, the error of using these geoid models near the lake shore is expected to be larger.

\subsection{Vertical Motion}

Both the water level gauges and GPS buoy measure- ments are relative to the onshore benchmarks and reference stations, respectively. Both measurements are not sensitive to the local vertical motion of the land, and thus, the vertical motion needs to be accounted for externally. In this area, there is a known long-term land motion called post-glacial rebound (PGR) or glacial isostatic adjustment (GIA). It is a physical phenomenon that the solid Earth is exhibiting a viscoelastic rebound and is still returning to the isostatic equilibrium due to the deglaciation of the Larentia ice sheet accumulated in this region during the last glacial maximum. Recent analysis using T/P satellite altimetry and 50 longterm lake gauge records provides a lake-wide vertical motion estimate of the entire Great Lakes (Kuo et al. 2008). The local vertical motion in the southern bank of Lake Erie is estimated to be $0.2 \mathrm{~mm} \mathrm{yr}^{-1}$ (subsidence). Vertical motion of coastal region could also be substantial due to erosion, subsidence due to hydrological extraction, tectonic, and other phenomena. In this study, we simply adopt the measurement model by Kuo et al. (2008) to account for the crustal deformation in Lake Erie.

\subsection{Comparison of Mean Lake Level from Various Sources}

This section compares the mean lake level from various sources, including the water level gauge records, satellite altimeter data, and the mean lake level derived from a GLFS lake circulation model.

Fig. 6 presents the mean lake level height observed from the valid observations found in the three ground tracks of satellite altimeter T/P in Lake Erie, as well as the data observed by 15 coastal water level gauges. The time span of such data is from 1999 to 2001. A geoid model, GEOID03, is applied to the T/P data in the figure only for the purpose of display. Despite that the gauges are surrounding the lake and the T/P footprints are crossing Lake Erie, we analyzed the lake level observed by both to see if they are consistent. We followed the procedures and applied the corrections described in Guman (1997) to process T/P data except for the ocean tide correction, since no such correction is provided 
Table 2. Error budget of converting water level gauge IGLD85 record to geocentric height in Lake Erie.

\begin{tabular}{|c|c|c|}
\hline & Error sources & Error budget \\
\hline \multirow{2}{*}{ IGLD85 to NAVD88 } & Hydraulic corrector $\left(H_{C}\right)$ & $1: 1$ ratio \\
\hline & Gravity & $2 \mathrm{~mm} / 10 \mathrm{mgal}$ \\
\hline \multirow{2}{*}{ NAVD88 to geocentric } & Geoid model & $>24 \mathrm{~mm}^{*}$ \\
\hline & GPS buoy & mm-level \\
\hline Vertical motions & Post-glacial rebound & $0.4 \mathrm{~mm} / \mathrm{yr}^{* *}$ \\
\hline
\end{tabular}

* RMS error when fitting GEOID03 to GPS benchmarks (Roman et al. 2004).

** RMS error of estimate for vertical motions (Kuo et al. 2008).

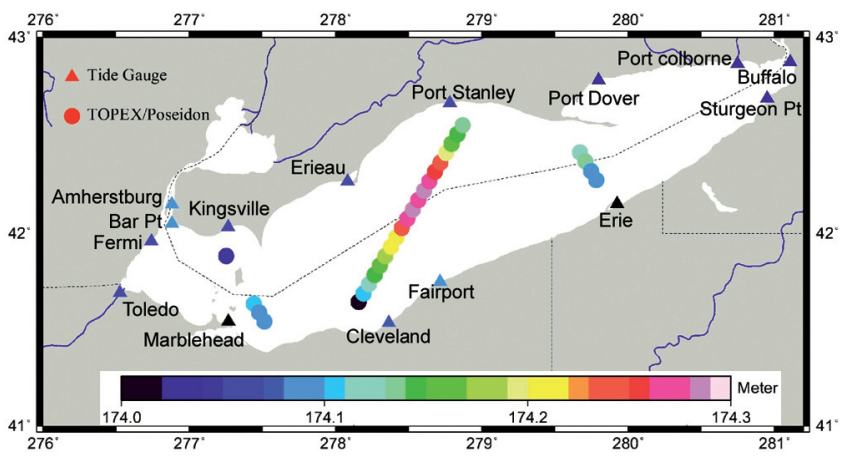

Fig. 6. Color-coded mean water derived from water level gauges (triangles) and T/P satellite altimeter valid footprints (circles) in Lake Erie. The time span is from 1999 - 2001. in the inland lakes. In order to compare the gauge records to the $\mathrm{T} / \mathrm{P}$ observations, means were calculated spatially for the entire Lake Erie with data from T/P and from the gauge records. The mean-removed time series derived from $\mathrm{T} / \mathrm{P}$ and from the gauge were plotted against time (1992 - 2003) according to the least squares approach in Fig. 7. It was intended to represent the trend of the lake level (or lake level variation). A good agreement was found: difference of means is $2.5 \pm 3.2 \mathrm{~cm}$ and the correlation is 0.994 . These indicate a good consistency of lake level variation between the gauge records and $\mathrm{T} / \mathrm{P}$ observations.

The comparison of the results presented below from measured water level gauges and altimetric data with modeled water surfaces along with subsequent model evaluations is a natural research extension and well beyond the scope and intent of this paper. This research is currently being undertaken by $\mathrm{V}$. Velissariou in her dissertation work under the supervision of the co-author K. Bedford. An initial comparison is described below, also reported by Niu et al. (2003), based on the lake model data provided by V. Velissariou.

The GLFS model describes the lake level and its variation in a $2 \times 2 \mathrm{~km}$ grid. Water levels are calculated as the sum of a chosen reference elevation plus the water temporal

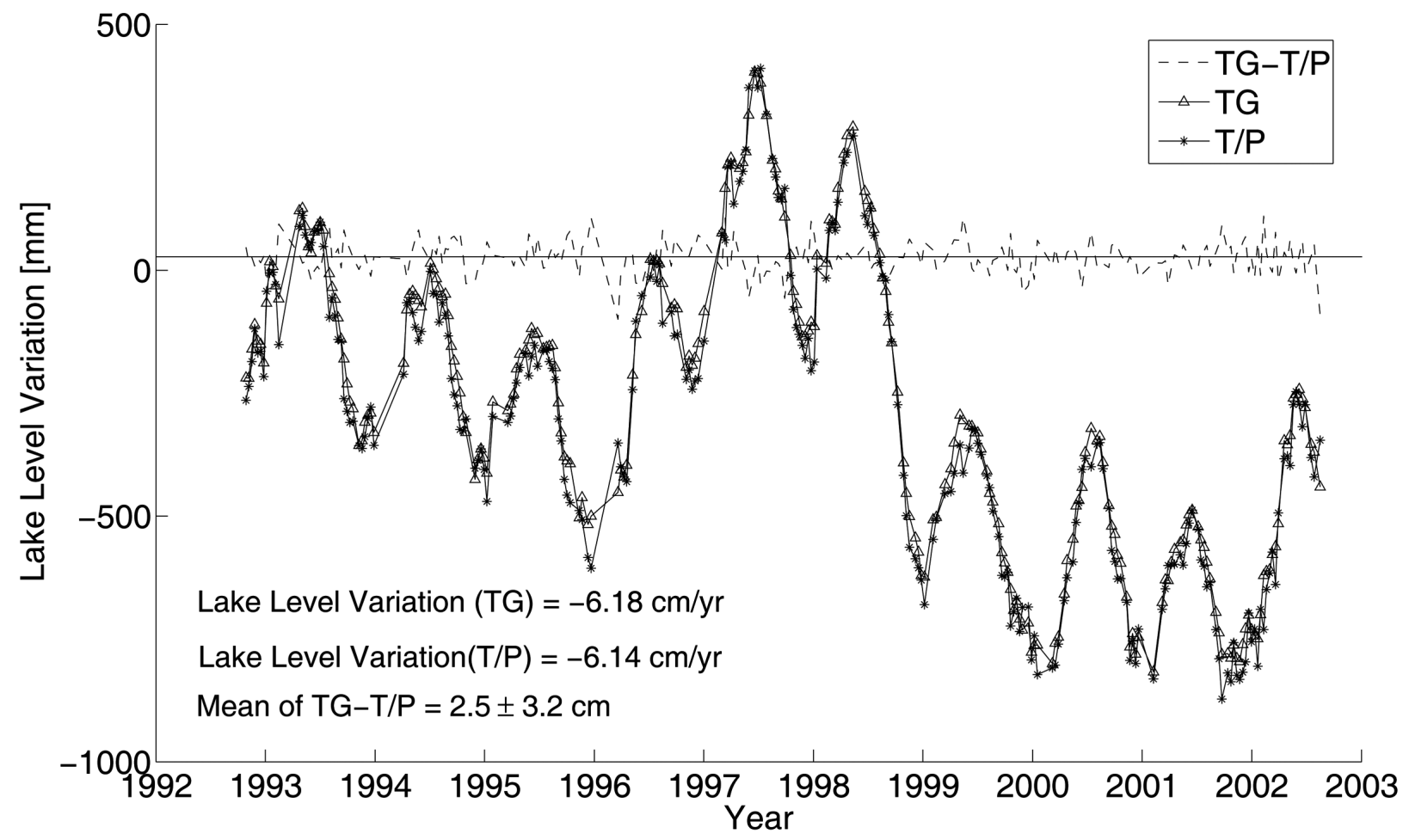

Fig. 7. The mean-removed lake levels from the gauges (TG) and T/P altimeter with good agreement: Difference of means is $2.5 \pm 3.2 \mathrm{~cm}$ and the drifts are -6.2 and $-6.1 \mathrm{~cm} \mathrm{yr}^{-1}$ for the gauges and $\mathrm{T} / \mathrm{P}$, respectively. The correlation between the two data sets is 0.994 . 
variation. The reference elevation is determined daily as the weighted average of the hourly water levels observed from three gauge stations, namely, Toledo, Ohio, Cleveland, Ohio, and Buffalo, New York, USA. The number and the location of the gauges and the weighting scheme have been selected in order to minimize the wind set up errors in the gauge readings and optimize the estimations of the mean lake level (Croley 1987). A mean (1999 - 2001) lake surface was generated with kriging for the GLFS model (Fig. 8a). Similarly, a mean lake surface was also generated with kriging with hourly water level gauge records (Fig. 8b). The difference between them is shown in (Fig. 8c). We found that the average disagreement is $2.7 \mathrm{~cm}$ with a maximum of $9 \mathrm{~cm}$.

Since the GLFS model is given in a grid in the lake but the water level gauges are surrounding the lake, the comparison based on each gauge location inevitably requires some sorts of interpolation. Since kriging produces the optimal result (Cressie 1993), we opted to compare on the surface (interpolated) level. The possible causes for the disagreement include the model error, observations used in the GLFS model, observations of the water level gauges, and spatial interpolation with kriging.

Similarly, the GLFS surface (Fig. 8a) is compared to that derived from T/P and the water level gauges (Fig. 8d). As we combined the lake level observed by the satellite technique (T/P) and the conventional method (water level gauges) to produce the surface in Fig. 8d, we had to incorporate a geoid model, namely, GEOID03, to accommodate their reference difference. Fig. 8e illustrates the difference between the GLFS mean lake surface and the surface based on $\mathrm{T} / \mathrm{P}$ and water level gauges. It was found the average difference was $-7.2 \pm 7.2 \mathrm{~cm}(\mathrm{~T} / \mathrm{P}$ surface being higher) with the largest difference of $28.2 \mathrm{~cm}$, which occurred in the middle of Lake Erie. The main cause of the discrepancy is the inconsistency in the reference surfaces: the model refers to its reference elevation defined by the elevation of the three gauges mentioned above, whereas the surface generated with data from T/P and from the water level gauges is calculated based on GEOID03. Since no gravity data were incorporated in the model development of GEOID03, it could be deficient especially in the middle of the lake. This is also evident in the Great Lakes when the actual altimetermeasured lake surface is compared to the much smoothed geoid models (Fig. 9). The large discrepancies indicate that the used geoid models lack the fine resolution that is compatible with the altimeter-measured lake surface. On the other hand, the meteorological data used for the circulation model may not have adequate spatial or temporal sampling to predict the detailed surface changes in the middle of the lake, resulting, in part, the 28 -cm discrepancy in the center of Lake Erie. Other causes include the errors of the vertical datum (NAVD88) and observations used for the GLFS modeling, geoid model, and observations in $\mathrm{T} / \mathrm{P}$ and the water level gauge measurements.

\section{CONCLUSIONS}

The method of accurate linking of water level to the shoreline datum is presented in this paper using geoid models, GPS buoy and T/P altimeter. The link of various data sets in the coastal area is important and has the potential to integrate various geospatial data to benefit the applications such as lake forecasting and hydrological modeling, environmental monitoring, coastal zone management, flood mitigation, relief dispatch during and after disasters, and
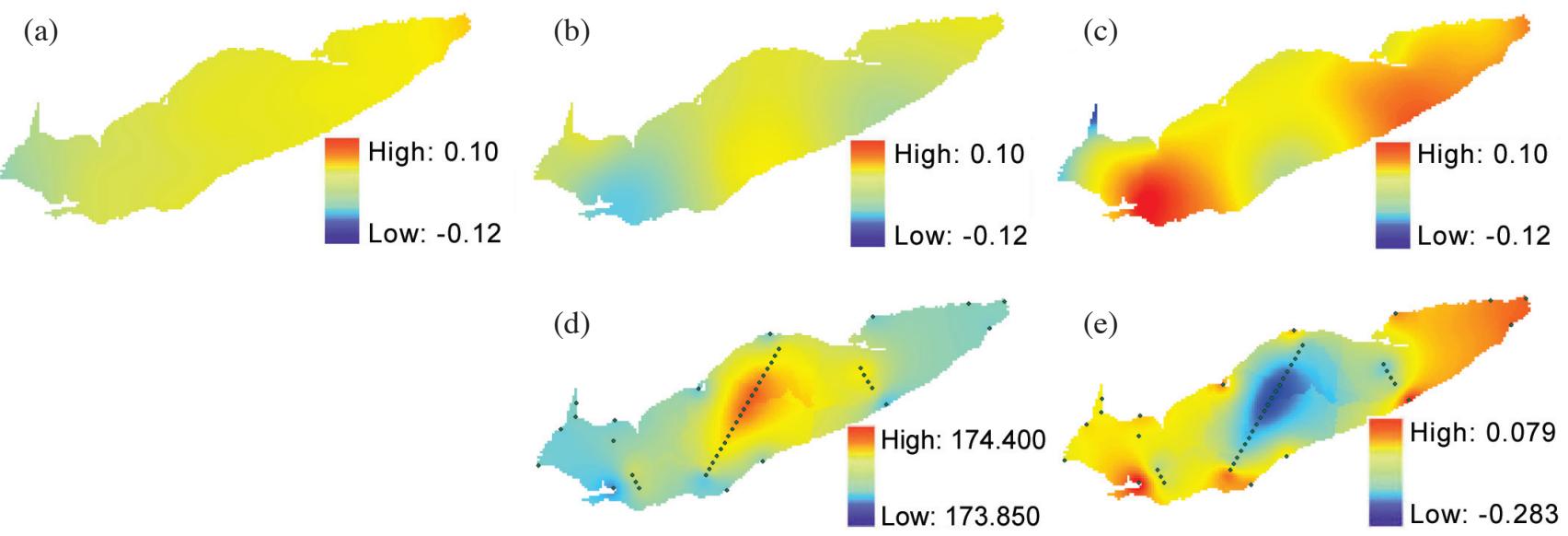

Fig. 8. Mean lake water level with data from 1999 - 2001 and comparisons (Niu et al. 2003): (a) GLFS model with respect to the chosen reference elevation; (b) surface derived from water level gauges refers to the same reference elevation in Fig. 8a; (c) difference between Fig. 8a and Fig. 8b; (d) mean lake surface derived from T/P and gauges in NAVD88; and (e) difference between Fig. 8a and Fig. 8d. Dots in Figs. 8d and e represents the $\mathrm{T} / \mathrm{P}$ footprints and gauge locations. The unit for all is in meters. 

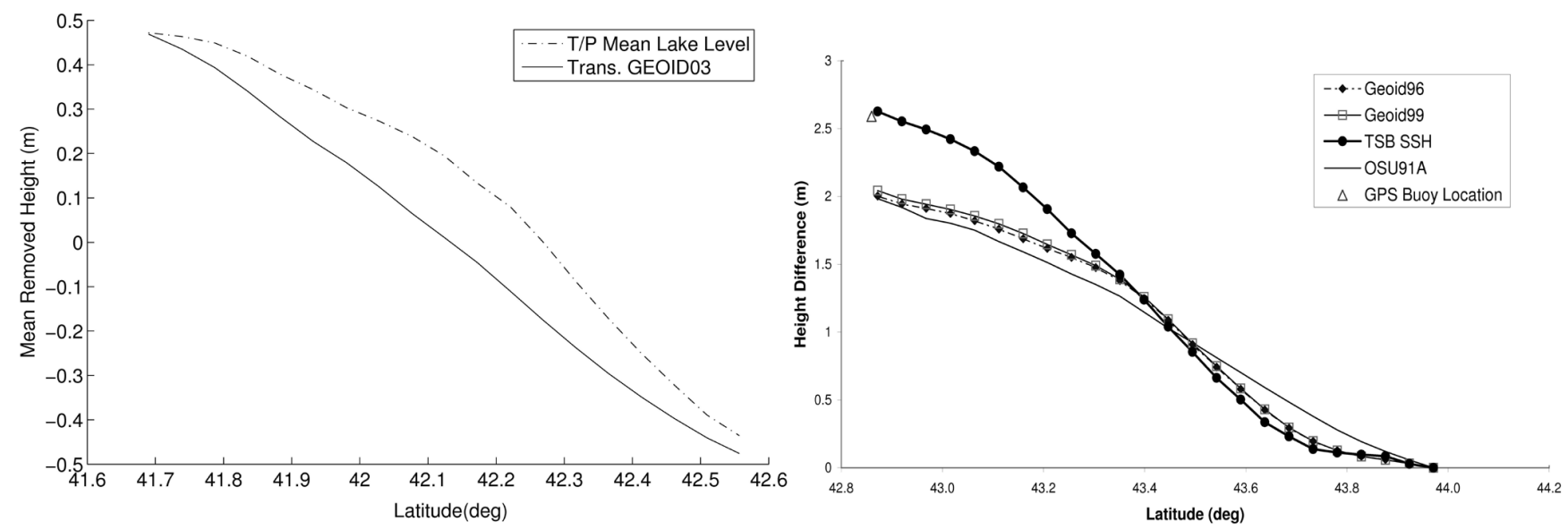

Fig. 9. Comparison of mean-removed lake level measured by T/P to geoid models in Lake Erie (left) and Lake Michigan (right). SSH stands for Sea (lake) Surface Height, which is measured by T/P over the large water bodies including lakes and oceans. In Lake Erie, the mean lake profile from Pass 193 of T/P is compared to the coordinate-transformed GEOID03. In Lake Michigan, the mean lake profile from Pass 239 of T/P Side B (TSB) is compared to geoid models. The heights are shifted at an arbitrarily chosen latitudinal parallel (Cheng 2001). GEOID96 and GEOID99 are predecessors of NGS' GEOID03 model. The details of OSU91A can be found in Rapp et al. (1991).

governmental decision-making. The use of geocentric satellite observations such as satellite altimetry, GPS buoy, and remote sensing imageries requires an accurate local geoid model in a sufficient resolution when integrating with water level gauge and DEM data, which are traditionally defined in an orthometric system, i.e., NAVD88. The discrepancy of geoid height estimated with a GPS buoy floating near a water level gauge is within $<2 \sigma$ of the current GEOID03 model at the Marblehead and Cleveland gauge locations. It represents an efficient way to improve the future vertical datum with $\mathrm{cm}$ level accuracy in the coastal area or the area where leveling is hard to carry out. The mean disagreement between the GLFS circulation model and the surface generated by kriging with 15 water level gauges is $2.7 \mathrm{~cm}$. However, when T/P altimeter lake surface measurements are incorporated during the same time span, the mean discrepancy enlarges to $7.2 \mathrm{~cm}$ with the maximum difference of $28 \mathrm{~cm}$ in near the center of the lake, presumably due to geoid model error on the lake. The current limitation of more accurately linking water surface to shoreline is the insufficient knowledge of geoid in the current models. The developed methodology of using water level gauge record, GPS buoy, and satellite altimetry, with suitably distributed gauge locations, is anticipated to be applicable to other lakes and the world's coastal regions.

Acknowledgements The authors acknowledge the constructive comments from J. Guo and another anonymous reviewer. We thank valuable comments from D. Conner and D. Roman of the National Geodetic Survey, and V. Velissariou of the Ohio State University for generously providing lake circulation data from the Great Lakes Forecasting System model for this study. This research is supported, in part, by the grant from the Information and Intelligent
Systems Digital Government Program (IIS-0091494) of the National Science Foundation of the US, the Ohio State Sea Grant (No. R/CE-5) funded by National Oceanic and Atmospheric Administration, and National Aeronautics and Space Administration of the US through the Physical Oceanography (JASON-1) and the Interdisciplinary Science Programs (JPL-1265252, NNG04GN19G), and the grant from the National Science Council of Taiwan (NSC 95-2119-M-194-006).

\section{REFERENCES}

Bedford, K. W., C. C. Yen, J. Kempf, D. S. Schwab, R. Marshall, and C. Kuan, 1990: A 3D-stereo graphics interface for operational Great Lakes forecasts. In: Spaulding, M. (Ed.), Coastal and Estuarine Modeling, Amer. Soc. of Civil Engineers, New York, 248-257.

Calmant, S., K. Cheng, G. Jan, C. Kuo, C. Shum, Y. Yi, V. Ballu, and M. N. Bouin, 2004: Comparison of sea surface heights derived from satellite altimetry and from ocean bottom pressure gauges: The SW Pacific MOTEVAS Project. Mar. Geodesy, 27, 597-613, doi:10.1080/01490410490883379.

Chelton, D. B., J. Ries, B. Haines, L. L. Fu, and P. Callahan, 2001: Satellite altimetry. In: Fu, L. L., and A. Cazenave (Eds.), Satellite Altimetry and Earth Sciences: A Handbook for Techniques and Applications, Academic Press, San Diego, 1-131.

Cheng, K., 2001: Radar altimeter absolute calibration using GPS water level measurements. Master Thesis, Department of Civil and Environmental Engineering and Geodetic Science, The Ohio State University, Columbus, Ohio, USA, 94 pp. 
Cheng, K., 2004: GPS buoy campaigns for vertical datum improvement and radar altimeter calibration. Geodetic Science Report No 470, The Ohio State University, Columbus, Ohio, USA, 74 pp.

Cheng, K., 2005: Analysis of water level measurements using GPS, Ph.D. Thesis, Department of Civil and Environmental Engineering and Geodetic Science, The Ohio State University, Columbus, Ohio, USA, 184 pp.

Coordinating Committee on Great Lakes Basic Hydraulic and Hydrologic Data, 1995: Establishment of International Great Lakes Datum (1985). Chicago, Illinois, USA, 48 pp.

Cressie, N. A., 1993: Statistics for Spatial Data, Revised Edition, A Wiley-Interscience Publication, New York, 887 pp.

Croley, T. E., 1987: Wind set-up error in mean lake levels. J. Hydrol., 92, 223-243.

Garcia-Lopez, R. V., 1997: Determination of vehicle acceleration by using the GPS phase acceleration. Geodetic Science Report No 440, The Ohio State University, Columbus, Ohio, USA, 62 pp.

Guman, M. D., 1997: Determination of global mean sea level variations using multi-satellite altimetry. Ph.D. Thesis, The University of Texas at Austin, Austin, Texas, USA, 195 pp.

Heiskanen, W. A., and H. Moritz, 1987: Physical Geodesy, reprinted, Institute of Physical Geodesy, Technical University, Graz, Austria, 364 pp.

Jekeli, C., 2000: Heights, the geopotential, and vertical datums. Geodetic Science Report No. 459, The Ohio State University, Columbus, Ohio, USA, 34 pp.

Kuo, C. Y., C. K. Shum, A. Braun, K. C. Cheng, and Y. Yi, 2008: Vertical motion determined using satellite altimetry and tide gauges. Terr. Atmos. Ocean. Sci., 19, 21-35, doi: 10.3319/TAO.2008.19.1-2.21(SA).

Li, R., R. Ma, and K. Di, 2002: Digital tide-coordinated shoreline. Mar. Geodesy, 25, 27-36.

Mader, G. L., 1986: Dynamic positioning using Global Positioning System carrier phase measurements. Manuscr. Geodaet., 11, 272-77.

Moritz, H., 1992: Geodetic reference system 1980. Bull. Geod., 66, 187-192.
National Geodetic Survey, 2001: Technical information page for G99SSS, GEOID99 and DEFLEC99, http:// www.ngs.noaa.gov/GEOID/GEOID99/tech.html (accessed on November 15, 2006).

National Geodetic Survey, 2003: What are datasheets, http:// www.ngs.noaa.gov/cgi-bin/datasheet.prl?Explain= DATASHEET (accessed on November 15, 2006).

Niu, X., C. Kuo, V. Velissariou, R. Li, K. Bedford, and C. K. Shum, 2003: Multi-source coastal data analysis. Proceedings of the NSF National Conference for Digital Government Research (dg.o 2003), May 18 - 21, in Boston, Massachusetts, USA. Also available online at http://www.diggov.org/library/library/dgo2003/ (accessed on April 26, 2007), 227-230.

Parker, B., D. Milbert, K. Hess, and S. Gill, 2003: National VDatum-The implementation of a national vertical datum transformation database. Paper presented in US Hydro 2003 Conference, March 23 - 27, in Biloxi, Mississippi, USA.

Rapp, R. H., Y. M. Wang, and N. K. Pavlis, 1991: The Ohio State 1991 geopotential and sea surface topography harmonic coefficient models, Geodetic Science Report No. 410, The Ohio State University, Columbus, Ohio, USA, 47 pp.

Roman, D. R., Y. M. Wang, W. Henning, and J. Hamilton, 2004: Assessment of the new national geoid height model, GEOID03. Paper presented at 2004 ACSM/ TAPS Conference and Technology Exhibition, April 16 - 1, in Nashville, Tennessee, USA.

Shum, C., Y. Yi, K. Cheng, C. Kuo, A. Braun, S. Calmant, and D. Chambers, 2003: Calibration of Jason-1 altimeter over Lake Erie. Mar. Geodesy, 26, 335-54.

Soler, T., J. D. Love, L. W. Hall, and R. H. Foote, 1992: GPS results from statewide high precision networks in the United States. Proc of the Sixth International Geodetic Symposium on Satellite Positioning, Ohio State University, Columbus, Ohio, 2, 573-82.

Zilkoski, D. B., J. H. Richards, and G. M. Young, 1992: Results of the general adjustment of the North American Vertical Datum of 1988. Surv. Land Inform. Syst., 52, 133-49. 